50. Troughton, S. C., Nominé, A., Dean, J., Clyne, T. W. (2016). Effect of individual discharge cascades on the microstructure of plasma electrolytic oxidation coatings. Applied Surface Science, 389, 260-269. doi: https://doi.org/10.1016/j.apsusc.2016.07.106

51. Clyne, T. W., Troughton, S. C. (2018). A review of recent work on discharge characteristics during plasma electrolytic oxidation of various metals. International Materials Reviews, 64 (3), 127-162. doi: https://doi.org/10.1080/09506608.2018.1466492

52. Belozerov, V., Mahatilova, A., Sobol', O., Subbotina, V., Subbotin, A. (2017). Improvement of energy efficiency in the operation of a thermal reactor with submerged combustion apparatus through the cyclic input of energy. Eastern-European Journal of Enterprise Technologies, 2 (5 (86)), 39-43. doi: https://doi.org/10.15587/1729-4061.2017.96721

\begin{tabular}{|c|}
\hline 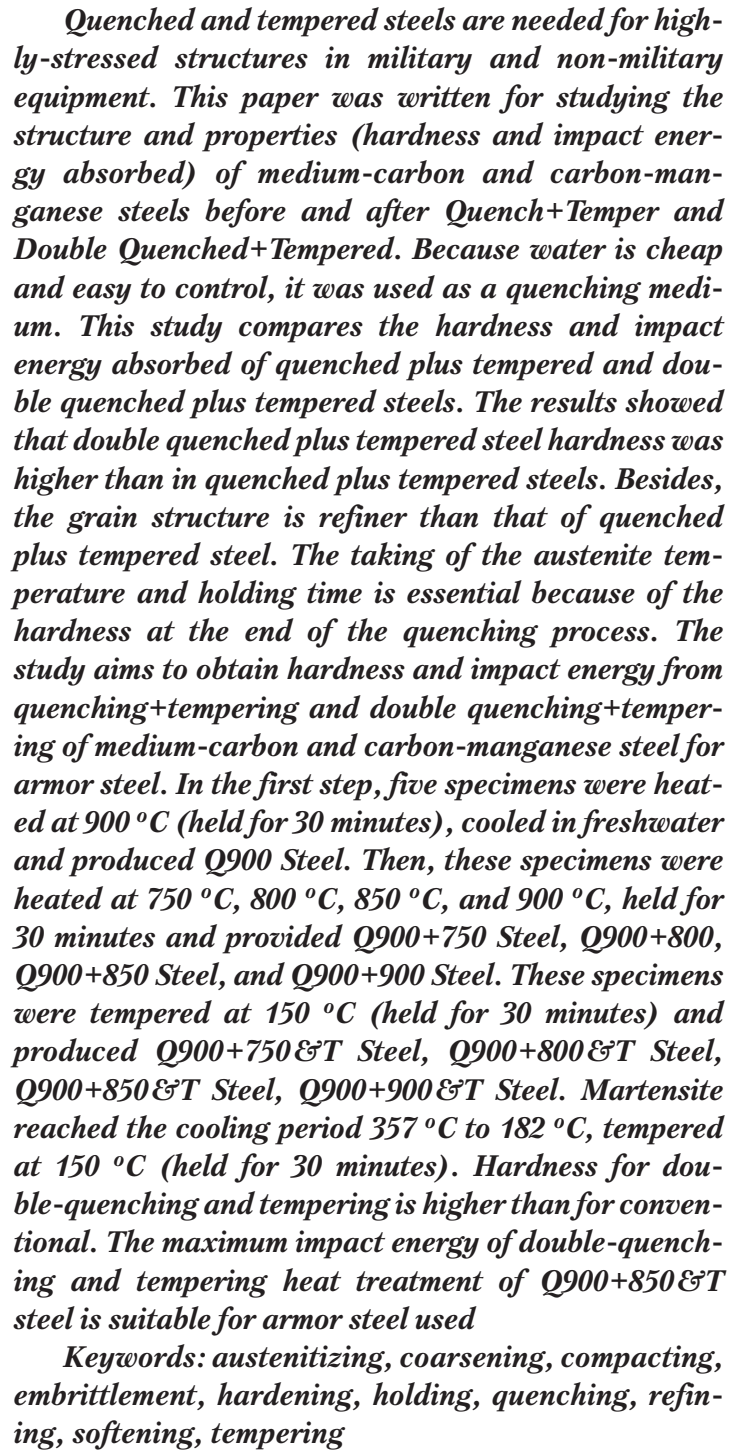 \\
\hline
\end{tabular}

Received date 01.09.2020 Accepted date 13.10.2020 Published date 30.10.2020
UDC 620

DOI: $10.15587 / 1729-4061.2020 .214223$

\section{COMPARISON OF THE STRUCTURE AND PROPERTIES BETWEEN SINGLE QUENCH+TEMPER AND DOUBLE QUENCH+TEMPER OF MEDIUM-CARBON AND CARBON-MANGANESE STEEL}

Yurianto Yurianto Doctor of Technical Sciences, Associate Professor* E-mail: yurianto_narimin@yahoo.com Sulardjak a S u lardjaka Doctor of Technical Sciences, Associate Professor, Lecturer*

E-mail: sulardjaka@lecturer.undip.ac.id

Susilo Adi Widyanto Doctor of Technical Sciences, Associate Professor* E-mail: susiloadiw@gmail.com

Padang Yanuar Magister of Technical Sciences, Lecturer Department of Mechanical Engineering

Semarang State Polytechnic

JI. Prof. Sudarto, SH, Semarang, 50275,

Central of Java, Indonesia

E-mail: padang.yanuar@polines.ac.id

*Department of Mechanical Engineering

Diponegoro University

JI. Prof. Sudarto, SH, Semarang, 50275,

Central of Java, Indonesia

Copyright (C) 2020, Yurianto Yurianto,

Sulardjaka Sulardjaka, Susilo Adi Widyanto, Padang Yanuar This is an open access article under the CC BY license (http://creativecommons.org/licenses/by/4.0)

\section{Introduction}

In Indonesia, medium-carbon and carbon-manganese steels are the raw materials for military equipment (e. g., main battle tank body, etc.) and commercial users (e. g., pressure vessel, chain conveyor, etc.). However, because of the difficulty of quenching and tempering on $1.500 \times 2,000 \mathrm{~mm}$ plates, mechanical properties were inconsistent. This means the mechanical properties generated between the first, second, and next batches are not consistent. This results in non-uniform product characteristics, so the market's selling value cannot compete with other steel industries. Also, the hardness and impact energy (very important in armored steel products) are not uniform.

Medium-carbon and carbon-manganese steels are the raw materials for armored steel. However, due to the difficul- 
ty of quenching and tempering on plates of $1.500 \times 2,000 \mathrm{~mm}$ in size, mechanical properties were inconsistent - the structure and properties of the first, second, and next batches are not consistent. Consistency of microstructure and properties will produce the low quality of steel product characteristics like this causes the selling value in the market cannot compete with other industries.

Mechanical properties need to be consistent with the product's demands (exceptionally high hardness and strength steels such as armor steel for military equipment), two of which are hardness and impact energy. For the manufacture of armored steel, these two properties are indispensable. Based on heat treatment, armored steels are produced by quench and temper (both can increase steel toughness). Quenching has hard martensite, and stress releases and expands ductility through tempering. The double quench creates a smooth quench steel structure [1].

Therefore, this study is devoted to comparing the level of hardness and impact energy absorbed in medium-carbon and carbon-manganese steels after quench+temper and double quench+temper heat treatment, the grain structure of the material is improved after double quenching. This research is a comparative study between quenched+tempered steel (used in factories) and double quenched+tempered steel (proposed) with medium-carbon steel and carbon-manganese steel materials. The research limitation is that the quenching medium used is water (currently used in factories). Water is chosen because it is cheap, has good thermodynamic properties (and does not interfere with the environment), and is easy to control. All parameters are the same as those used in the factory, but what is different is the double quenching heat treatment process proposed in this study.

\section{Literature review and problem statement}

The transformation of austenite to martensite causes the hardness increase of medium-carbon and carbon-manganese steels through the quenching process. Then tempering is carried out to increase ductility and high strength steels are obtained. When discussing high-strength steel, it is essential to realize that the definition of high strength depends entirely on how the steel is used [2]. The papers [3, 4] state that the strength of the martensite structures is dominated by carbon content and temperature range (martensite start-martensite finish). While Krauss wrote that to produce high-strength microstructures, low-temperature tempering has been triggered: hardness and standard features that depend on carbon from microstructural systems hardened in steel [5]. Martensite is formed when the steel is aerated and cooled at a speed high enough to avoid ferrite, pearlite, and bainite [6,7], then it is tempered. After tempering, the hardness profile becomes more homogeneous due to the microstructural tempering effect [8]. Here the temper function is to remove the residual stress generated by the previous quenching process. The combination of quench and temper produces strong steel and high hardness. So that in recent years there has been an increasing demand for quenched and tempered steel (Q\&T Steel), used for very high-pressure structures, including applications in the construction of military and non-military equipment, due to its hardness and high energy absorbing properties, and exceptional toughness [9-11].

The heating temperature needs to consider the number of soluble solids and grain refinement [12]. Therefore, steel that is processed by quenching and tempering is intended to obtain mechanical strength [13]. The martensite structure is formed during the quenching process, and the hardness of the full martensite structure is determined only by the steel's carbon content (low carbon), and it is equal to the maximum hardness of the steel [14]. Meanwhile, the refinement of the grain structure of quenched and forged martensitic steels increases the strength and toughness expected, especially in everyday life [15]. The increase in strength can be due to the compaction of the microstructure. The optimum heat treatment parameters with a substantial effect on hardness are the austenite temperature of $900{ }^{\circ} \mathrm{C}$ and tempering temperature of $125^{\circ} \mathrm{C}$ with a hardness prediction of $536.00 \mathrm{BHN}$. The optimal heat treatment parameters that strongly influence the impact energy are the austenite temperature of $900{ }^{\circ} \mathrm{C}$ and tempering temperature of $175^{\circ} \mathrm{C}$ with an impact energy prediction of 30.50 Joule [16].

The researchers discussed the hardness and impact energy absorbed of medium-carbon and carbon-manganese steels after experiencing a single quench plus temper with double quench and temper. This difference is quite significant, especially in changes in microstructural texture. As a result, this heat treatment will affect the shape of the microstructure and properties (in this case, the hardness and impact energy absorbed). The hardness and impact energy absorbed were very high when removing the armor.

This paper discusses the study results about the change of microstructure and properties caused by single quenched and double quench continued by tempering of medium-carbon and carbon-manganese steel. This heat treatment produces Quenched+Tempered Steel (called Q\&T Steel) and Double Quenched+Tempered Steel (called DQ\&T Steel). The hardness and impact energy absorbed are essential to consider to build bullet resistant steel for armor steel.

There has been much research on medium-carbon and carbon-manganese based steels. Still, no one has yet investigated the change in structure and properties (in relation to hardness and impact energy absorbed) of quenched and tempered armor steel and double quenched and tempered armor steel. The difficulty of setting the austenite to a certain temperature (in the refine austenite area) results in a different grain size of austenite; therefore, it is necessary to experiment with the experience required. For this reason, it is said that this research is something new (novelty).

The study is conducted to increase the hardness and ductility of medium-carbon and carbon-manganese steels after quenching + temper and double quenching + tempered to obtain tough steel armor. Formidable here is a combination of hardness and strength, and this is very relevant in the quest to obtain armor. Therefore, it is essential to set the austenite's temperature properly so that to obtain as much martensite as possible through the austenite transformation during quenching.

\section{The aim and objectives of the study}

The aim of the study is to compare the structure and properties between single quench+temper and double quench+temper of medium-carbon and carbon-manganese steel.

To achieve this aim, the following objectives are accomplished:

- to determine the period of martensite formation during quenching; 
- to determine the hardness of Medium-Carbon and Carbon-Manganese Steel, Q\&T Steel, and DQ\&T Steel;

- to determine the impact energy of Medium-Carbon and Carbon-Manganese Steel, Q\&T Steel, and DQ\&T Steel.

\section{Formulas used in research}

From the results of the research, data processing includes: $\mathrm{Ar}_{3}$ transformation temperature, martensite start and finish temperature $(M s)$ and $\left(M_{F}\right)$, and impact energy absorbed $(E)$ using the formula (1) - (4).

The transformation temperature $\left(A r_{3}\right)$ and martensite start temperature $\left(M_{s}\right)$ of low-alloy steels are shown in Equation 1 and 2, respectively, as shown in the paper by Sampath [17],

$$
A_{r 3} \backsim(910-310 \mathrm{C}-80 \mathrm{Mn}-80 \mathrm{Mo}-55 \mathrm{Ni}-20 \mathrm{Cu}-15 \mathrm{Cr}){ }^{\circ} \mathrm{C}(1)
$$

and

$$
\begin{aligned}
& M_{S}=(561-474 \mathrm{C}-33 \mathrm{Mn}-17 \mathrm{Ni}-17 \mathrm{Cr}-21 \mathrm{Mo}){ }^{\circ} \mathrm{C}, \\
& M_{F}=M s-\left(175^{\circ} \mathrm{C} \text { to } 265^{\circ} \mathrm{C}\right) .
\end{aligned}
$$

The value of the impact energy absorbed $(E)$ using Charpy impact test is calculated using the following equation (4),

$$
E=W \times R \times(\cos \beta-\cos \alpha),
$$

where $W$ is hammer weight $(\mathrm{kg}) ; R$ is hammer center distance (m); $\alpha\left(^{\circ}\right)$ and $\beta\left({ }^{\circ}\right)$ are actual capacity lift angle and angle after contact, respectively.

\section{Material and method}

\section{1. Material}

The research material used is medium-carbon and carbon-manganese steel with a $10 \mathrm{~mm}$ thickness and made by the Indonesia steel industry.

\section{2. Method}

Research implementation methods (including testing, data processing, and discussion of test results) were carried out in the following steps.

The first step is to make five specimens measuring $120 \times 100 \times 8 \mathrm{~mm}$ (cutting using a wire cutting machine to get a flat and smooth specimen surface).

The second step. The specimens in the first step were divided into five equal sizes. The five samples were heated together in a heater at a temperature of $900{ }^{\circ} \mathrm{C}$ and held for $30 \mathrm{mi}-$ nutes, then cooled in freshwater. The end of cooling produced five specimens of Quenched $900^{\circ} \mathrm{C}$ Steel ( $Q_{900}$ Steel). Then one of the samples was tested for metallography, hardness, and impact.

The third step. One specimen was heated to $150{ }^{\circ} \mathrm{C}$ and cooled in the atmosphere, producing Quenched and Temper Steel (Q $Q_{900} \& \mathrm{~T}$ Steel). This specimen is made using single quenched and tempered steel.

The fourth step. The remaining four specimens were heated at $750{ }^{\circ} \mathrm{C}, 800{ }^{\circ} \mathrm{C}, 8500^{\circ} \mathrm{C}$, and $900^{\circ} \mathrm{C}$ held for 30 minutes, and each specimen produces $Q_{900+750}$ Steel, Q $_{900+800}$ Steel, Q ${ }_{900+900}$ Steel, and Q ${ }_{900+900}$ Steel.
The fifth step. After the second quenching, each specimen was heated to $150{ }^{\circ} \mathrm{C}$, and produces: $Q_{900+750} \& \mathrm{~T}$ Steel, $\mathrm{Q}_{900+800} \& \mathrm{~T}$ Steel, $\mathrm{Q}_{900+850} \& \mathrm{~T}$ Steel and Steel $\mathrm{Q}_{900+900} \& \mathrm{~T}$ Steel.

The sixth step. Discussing and concluding the test results, especially regarding the comparison of hardness and impact energy between DQ\&T Steel and Q\&T Steel.

\section{3. Test equipment used}

The chemical composition of the research material was analyzed using the ARL 3460 optical emission spectrometer made in Switzerland. The microstructures of the specimens were examined after conventional polishing etching using a $3 \% \mathrm{HNO}_{3}$ solution. Metallurgical optical microscopes NIKON Epiphot have been employed for the purpose. Hardness surveys were conducted across the weld beads of all the weld coupons, ZWICK type Zhu micro-hardness Vickers at $500 \mathrm{~g}$ testing machines were used. Wolpert type PW 30/15 impact testing machines have been conducted using a V-notched specimen and hit by a hammer with $294 \mathrm{Nm}$, and the angle was measured when the sample ruptured.

\section{Research results}

Table 1 shows the test results for the chemical elements contained in medium-carbon and carbon-manganese steels. Furthermore, using formulas 1, 2, and 3, transformation temperatures were obtained: $A r_{3}, M_{S}$, and $M_{F}$, these temperatures determine the austenite zone closest to $A r_{3}$. The $T_{T}$ temperature was obtained based on the $M_{F}$ temperature. Tempering temperature only reduces the residual stresses from the previous quenching results, respectively, shown in Table 2.

Hardness testing on the test material is carried out before and after heat treatment and shown in the depth vs. hardness graph. These data are shown in Cartesian coordinates, as shown in Fig. 1.

The test results of impact energy absorbed in the material before and after heat treatment are shown on the diagram bar, as in Fig. 3.

According to the heat treatment, each specimen's metallography was used and shown in Fig. 4-11.

\section{Discussion of the research results}

Implementation of the research to completion, the results obtained in four groups of chemical elements contained; impact energy absorbed, hardness, and optical metallography.

\section{1. Transformation temperature}

The chemical compositions contained in the specimens show low ductility and weldability of carbon and manganese. The performance of steel is improved and has slightly decreased weldability due to chromium and molybdenum. Nickel decreases the critical cooling rate and does not form any carbide compounds in the steel. It remains soluble in ferrite, thereby strengthening and increasing the ferrite phase's toughness in construction steel. The shallow phosphorus content $(<1 \%)$ is safe against the risk of $\mathrm{Fe}_{3} \mathrm{P}$ deposits forming, which causes the steel to become brittle, increasing strength and machinability (also increasing corrosion resistance). The main chemical compositions present in steel are shown in Table 1. 
Chemical compositions of steel

\begin{tabular}{|c|c|c|c|c|c|c|c|c|}
\hline Element & Carbon & Chromium & Manganese & Molybdenum & Nickel & Phosphorus & Sulfur & Silicon \\
\hline wt \% & 0.293 & 0.550 & 1.412 & 0.193 & 0.279 & 0.014 & 0.008 & 0.329 \\
\hline
\end{tabular}

Based on chemical elements in the material, the $A r_{3}$, $M_{S}$, and $M_{F}$ temperatures were calculated according to the formulas (1)-(3), respectively, and the results are shown in Table 2.

Table 2

Transformation temperature

\begin{tabular}{|c|c|c|c|c|c|c|}
\hline Temperature & $A r_{3}$ & $M_{S}$ & Highest $M_{\text {月 }}$ Lowest $M_{F}$ & Average $M_{\text {F }}$ & $T_{T}$ \\
\hline${ }^{\circ} \mathrm{C}$ & 667 & 357 & 182 & 92 & 137 & 150 \\
\hline
\end{tabular}

The content of chemical elements affects the temperature of $A r_{3}$; the carbon element is the dominant one. The higher the carbon content, the lower $A r_{3}$, and directly reduces the temperature of the austenite. The higher the austenite temperature $\left(>A r_{3}\right)$, the coarser the austenite (the closer the temperature, the finer austenite will be obtained). If each of the conditions quenched, coarse and fine martensite is obtained respectively. However, it is not easy to obtain fine austenite by setting the austenite temperature close to $A r_{3}$. For this reason, researchers suggest performing optimization with statistical methods or computer programs. Knowing the temperature of $A r_{3}$, we can easily adjust the area of austenite to a temperature slightly above the calculated $A r_{3}$. The closer to $A r_{3}$, the finer the austenite (the further away from $A r_{3}$, coarse austenite is obtained). Therefore, it is essential to specify the austenite's fit temperature to get fine martensite.

$M_{S}$ to $M_{F}$ is martensite forming in the quenching period (in this research is water quenching), and compression stress is left. This stress causes compaction between structures during quenching, which causes slip and promotes cracking. Because there is no transformation after $M_{F}$, it can be used as a reference to determine the tempering temperature. This temperature does not defuse martensite, and only reduces the residual compression stress due to previous quenching. Therefore, the tempering temperature is chosen below $M_{F}$ to prevent the material softening due to martensite defused.

Based on the carbon content and alloying elements, the steel classification is mild steel $(0.15-0.30 \%$ carbon) [18] or medium-carbon and carbon-manganese steels $(\mathrm{C}=0.25-$ 0.45; $\mathrm{Mn}=1-1.7 ; \mathrm{Si} \leq 0.5)$ [19]. Based on the content of the specimen's chemical elements (medium-carbon and carbon-manganese steel), medium-carbon and carbon-manganese steels are classified. With a low carbon content, this steel can be treated with heat (heat treatment). This steel can be quenched safely by heat treatment (it does not leave cracks). Besides, the maximum temperature is $900{ }^{\circ} \mathrm{C}$, and below the evaporation temperature of the elements contained [20].

\section{2. Hardness}

The hardness depends on the austenite; the closer to $A r_{3}$, the hardness is slightly softer. The higher the austenite temperature, the higher the hardness value, and the more brittle it was. The transformation of austenite to martensite during quenching $\left(M_{S}-M_{F}\right)$ has high hardness and brittleness. The brittleness of martensite depends on the temperature po- sition of the austenite. Temperature $A r_{3}=667^{\circ} \mathrm{C}$, meaning slightly above that temperature is the austenite area. The temperature is closer to $\mathrm{Ar}_{3}$; the hardness is slightly softer. The higher the temperature of the austenite, the higher the hardness value and brittleness. Refined austenite produces finer martensite, and the toughness is higher. Coarse martensite has high hardness and brittleness; its toughness is lower than in fine martensite. The martensite formation process takes place from the $M_{S}$ to $M_{F}$ period; after $M_{F}$, there is no transformation. Therefore, to avoid decomposition of the martensite structure, the tempering temperature $\left(T_{T}\right)$ must be lower than $M_{F}$. At the $T_{T}$ temperature, the residual stress decreases. In the industry, tempering temperature to preserve as much martensite as possible is from $150{ }^{\circ} \mathrm{C}$ to $200{ }^{\circ} \mathrm{C}[5]$.

The highest hardness is achieved in the DQ\&T specimen, and indispensable for military and commercial applications that demand high hardness.

The surface hardness of the quenched and tempered steel was HV 436 (average), while the double quenched and tempered steel specimen was $497 \mathrm{HV}$. These results suggest that steels retain a high surface hardness even though the reheating temperature was lowered during the secondary quenching to ensure grain refinement. The surface area of the specimen is an immediate area for the transformation of austenite to martensite.

During quenching, refine carbonitride deposits occur. Austenitization at $900{ }^{\circ} \mathrm{C}$ and tempering at $125^{\circ} \mathrm{C}$ contribute to a substantial effect on the hardness of Q\&T Steel [16], and the closest temperature to $\mathrm{Ar}_{3}$ produced fine austenite. The water quenching of fine austenite provides the fine martensite, reduces the friction coefficient, and is suitable for wear resistance component (armor steel) [1]. The hardness fluctuation occurred (Fig. 1). But for the DQ\&T Steel specimens, more uniform than the Q\&T Steel. Overall, the second quenching is uniform in structure and hardness directly. Non-uniform hardness is due to the microstructure shapes and causes a decrease in the impact energy absorbed. Uniform hardness produces an increase in impact energy absorbed.

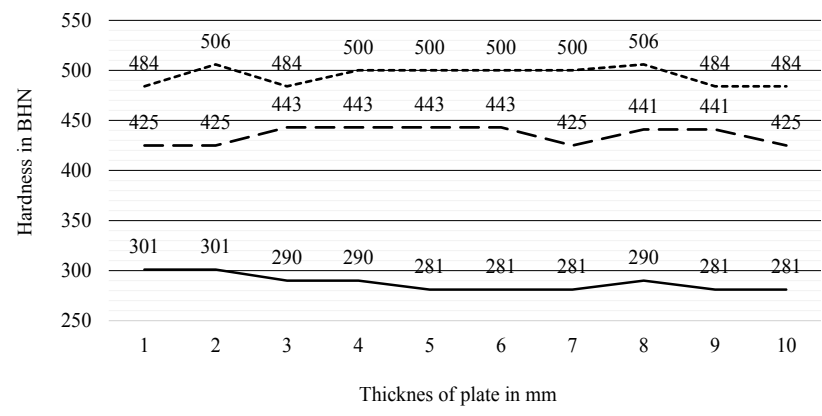

C Carbon-Medium and Carbon-Manganese Steel $\quad$ - -Q\&T Steel $\quad$--.-.DQ DQT Steel

Fig. 1. Hardness vs Dept of half thickness

Fig. 1 shows the hardness vs. distance - hardness measured from the surface to the thickness on standard (before heat treatment), Q\&T, and DQ\&T specimen. 


\section{3. Impact energy absorbed}

The impact survey is shown in the bar diagram of impact energy versus heat treatment type. Austenite temperatures of $900{ }^{\circ} \mathrm{C}$ and $175^{\circ} \mathrm{C}$ have a strong influence on energy. The results of the impact tests on the specimens show that the double quenched and tempered samples show the lowest values than carbon-manganese and quenched and tempered specimens - the increase in toughness caused by the martensite structure after quenching and tempering heat treatment process. The increase of impact energy absorbed can occur due to the inhomogeneous microstructure. Meanwhile, decreasing impact energy absorbed is due to inclusions (non-metal) or microvoids in the specimen.

The impact energy specimen is formed by following the standard dimensions, as shown in Fig. 2.
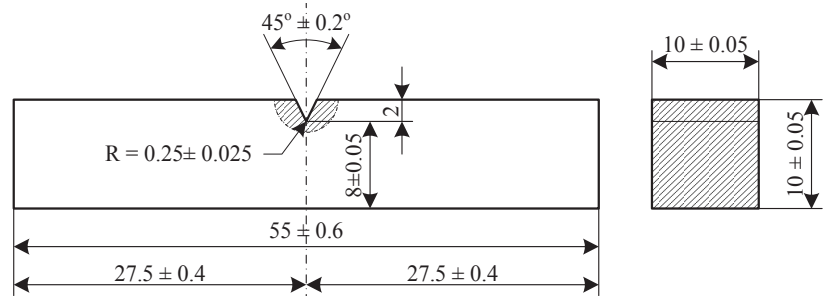

Fig. 2. Charpy impact test specimen [21]

Conventional and double quenching method produces brittleness that shows hardness increase. Therefore, ruptures can occur within a short time at a dynamic impact that exceeds the impact toughness limit. The highest impact value of Q\&T and DQ\&T steel is in $Q_{900+850} \& T$ Steel specimens and reached 43 Joules. There is martensite refinement in the zone closest to the $A r_{3}$ line. The lowest impact energy absorbed was obtained for $Q_{900+750} \& T$ Steel specimens. The low impact energy is due to the second austenitization close to $A r_{3}$, possibly a mixture of austenite $\gamma$ and the eutectoid structure $\alpha$, results in a decrease in hardness upon completion of quenching (since austenite is not completely transformed to martensite). The combination of hardness and strength is a specific mechanical property of steel, namely the steel's toughness for military and commercial equipment. Therefore, ductility is needed to achieve good toughness, as well as small martensite grain structures.

Microstructure, hardness, and impact energy absorbed change when the austenite temperature changes. So, the most important thing is to keep the temperature constant. The selected austenite temperature should be as close as possible to the $A r_{3}$ line for the second quenching. Impact energy absorbed of each standard and heat-treated specimen is obtained, and drawn in Cartesian coordinate as shown in Fig. 3.

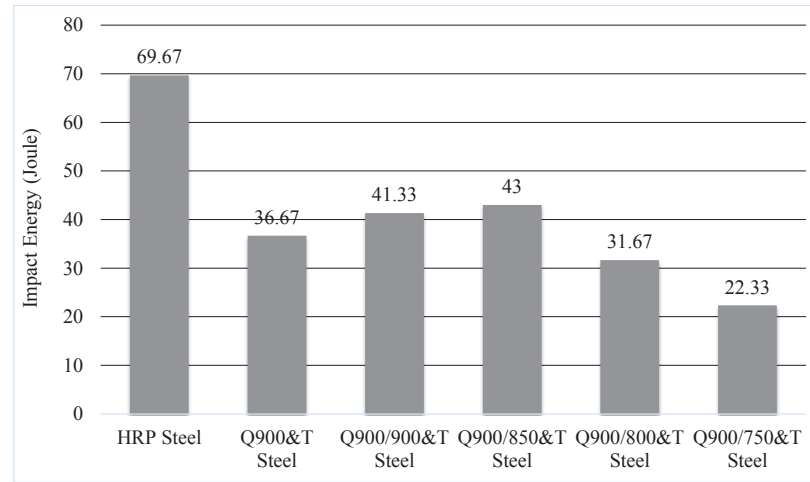

Fig. 3. Charpy impact test specimen ASTM E-23

\section{4. Metallography}

The results of the metallographic observations were applied to standard and heat-treated specimens. The force of the roller causes compaction between the grain structures, and flattened structures. The system's compression causes its hardness to increase (in fact, micro-cracks occur in transgranular). Light-colored (white) with small dots in the ferrite structure has a lower hardness than pearlite and indicating the process is in the austenite zone. Dark color with a flat shape (flat and group) shows the structure is pearlite. The ferrites dominate the microstructures with a lower hardness than the pearlites; it means that the hardness tends to be ferrite. The hardness of the standard specimen (standard steel) has quite ductile. The flattened structure poses the risk of longitudinal cracking. This risk decreases after quenching heat treatment (transformation of austenite to martensite) and temper (reduction of residual stress). The combination of quench and temper gives the steel toughness. The granular structure of ferrite, austenite, and pearlite, which elongates due to the roller's pressure during manufacture, is shown in Fig. 4.

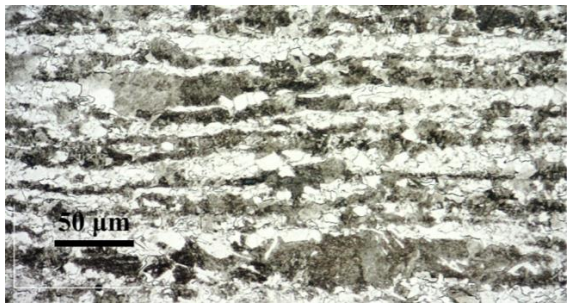

Fig. 4. Standard steel (before quench and temper heat treatment)

Fig. 5 shows a typical microstructure of the Q $_{900}$ steel specimen. Martensite grain size is proportional grain size before and after quenching. The austenite transformation failed because quenching is not perfect, then the hardness is not optimal. Two hardening modes during quenching are metallurgical and mechanical hardening - metallurgical hardening caused by martensite. Meanwhile, hardness due to shrinkage (i. e., the end of the quenching process) is mechanical hardening. Steel that is hard and brittle is challenging to manufacture (the disadvantage of quenched steel). Therefore, it is necessary to increase the elasticity and slightly decrease hardness, namely by tempering at a temperature of $150{ }^{\circ} \mathrm{C}$. A small reduction in hardness is due to the release of residual compression stress. The microstructural compaction due to quenching is reduced due to the activation of tempered heat, which causes stretching between structures.

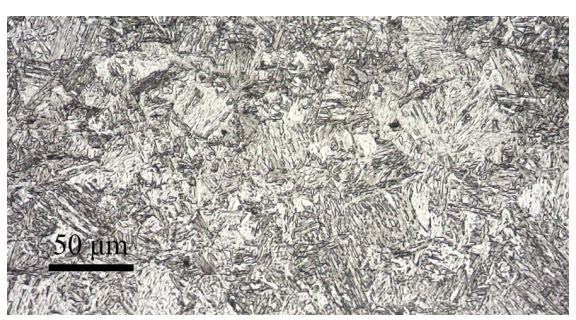

Fig. 5. Q900 Steel

The second austenitization set below the $A r_{3}$ line defuses martensite, and slightly above fine-grained austenite is obtained. At the end of double quenching, a martensite 
refinement occurred. Bright colored granules indicate that the austenite has failed to turn into martensite (because the quenching process cannot produce full martensite). The second austenitization at $750{ }^{\circ} \mathrm{C}$ defuses martensite (from the first austenitization) by heating below the eutectoid temperature. Temperature close to the eutectoid temperature (around $723^{\circ} \mathrm{C}$ ) is difficult to describe its structure. The second austenite causes the grain structure to become smaller; this is due to the diffusion of martensite when heating to austenite (below the $A r_{3}$ temperature to be precise). When heating exceeds $\mathrm{Ar}_{3}$, the austenite settles down and becomes martensite when rapidly cooled. Fig. 6 shows the microstructure of the steel $Q_{900+750}$ and displays refine martensite at the austenitization temperature near the $A r_{3}$ line.

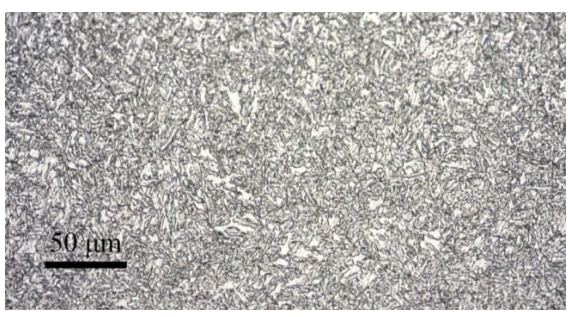

Fig. 6. Q900+750 Steel

The coarser martensite is due to higher austenitization after quenching is complete - coarse martensite due to a coarse austenite zone with higher temperatures (getting closer to its melting point). The results of non-uniform austenitization in-heterogeneous austenite after quenching produces non-uniform martensite (meaning the grain structure is not uniform). This second quenching result has an uneven hardness, is brittle, and difficult to manufacture (so it is rarely used). So it needs a little softening. In this study, tempering heat treatment at a temperature of $150{ }^{\circ} \mathrm{C}$ is considered. Tempering is a softening treatment (as long as it is below the eutectoid line) and reducing martensite and residual stresses. There was a defusion of martensite from the first quenching in the second quenching when the temperature rose to the austenite zone. Because the martensite slightly defuses, the result is slightly refiner martensite. Refiner martensite shows in flake shape (thin plate) and tends to absorb vibration (if used for components supporting dynamic load). The microstructure of the $Q_{900+800}$ Steel specimen is shown in Fig. 7.

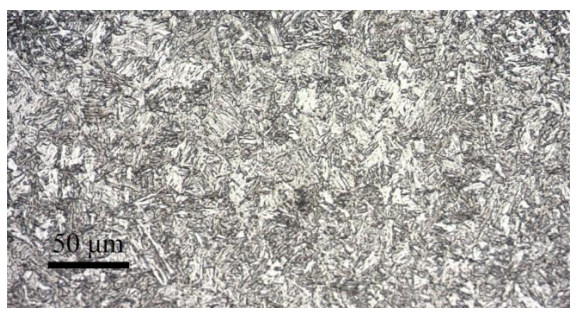

Fig. 7. $Q_{900+800}$ Steel

Fig. 8 shows the microstructure of the $\mathrm{Q}_{900+850}$ Steel specimen. The microstructures of $\mathrm{Q}_{900+850}$ and $\mathrm{Q}_{900+800}$ steels are similar because the temperature difference is $50{ }^{\circ} \mathrm{C}$; this makes a similarity in the shape of the microstructure. The second quenching converts the remaining austenite from the previous quenching $\left(900{ }^{\circ} \mathrm{C}\right)$ to martensite, and the fine grain structure is obtained. This fine grain will increase the ductility, which directly reduces the susceptibility to cracking. The microstructure is smaller than in $\mathrm{Q}_{900+800}$ Steel and $\mathbf{Q}_{900+850}$ steel specimen. Since the austenite temperature is similar to $Q_{900+850}$ Steel, and the structure as well. The fine microstructure of the $\mathbf{Q}_{900+900}$ Steel is extremely hard and brittle. Hardness and brittleness of steel can promote cracking, and the risk to fracture if used for construction. The martensite structure prior quenching dominates because of its hardness; it needs a little softening by tempering.

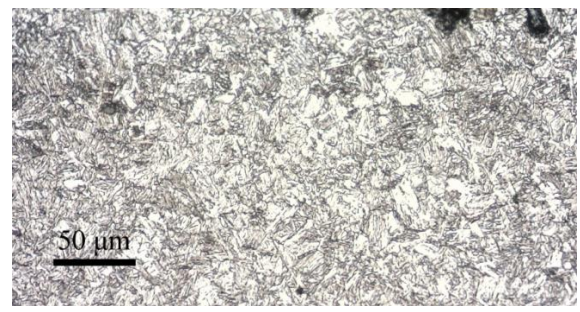

Fig. 8. $Q_{900+850}$ Steel

The microstructure is coarser and similar to the $\mathrm{Q}_{900+800}$ Steel and $\mathbf{Q}_{900+850}$ steel specimen. The $\mathbf{Q}_{900+900}$ Steel is extremely strong, yet too brittle. The martensite structure dominates because of its hardness; it needs a little softening (so that the ductility increases and easy to manufacture process). In order to use it, it takes a little tempering (reducing internal stress caused by prior quenching). As explained above, the higher second quenching temperature causes the grain structure to become too coarse. At the austenite temperature of $900{ }^{\circ} \mathrm{C}$, it is expected that after quenching as much martensite as possible will be obtained. The increasing amount of martensite made steel too hard and very difficult to work. The residual stress contained in the steel causes increased hardness due to compaction between structures. Q ${ }_{900+900}$ steel is too hard and brittle, rarely used because too difficult to manufacture process. For this reason, it is necessary to soften by removing a small amount of martensite and reducing residual stress by applying tempering heat treatment. Fig. 9 shows the microstructure of the $Q_{900+900}$ Steel specimen.

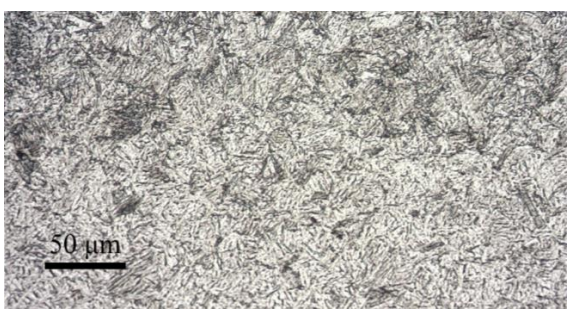

Fig. 9. Q900+900 Steel

Fig. 10 shows the $Q_{900+750} \& \mathrm{~T}$ specimen. The microstructure looks smaller than with single quenching $\left(\mathrm{Q}_{900}\right)$. Tempering at $150{ }^{\circ} \mathrm{C}$ has the property of reducing martensite. The compressive residual stress of this steel can be relieved by the tempering process. When heating to $150{ }^{\circ} \mathrm{C}$, a small amount of martensite defused (because the final temperature of martensite formation is $92{ }^{\circ} \mathrm{C}$ ). Tempering process producing hardness decreases due to martensite reduction and the residual stresses in the compression. Martensite defuses when tempering over $M_{F}$, the result is softening because diffusion in martensite and stress relieves. 


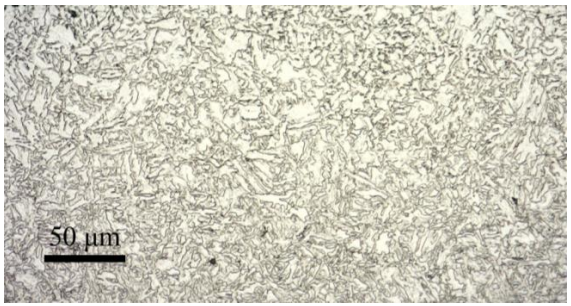

Fig. 10. $Q_{900+750} \& T$ Steel

Martensite slightly defused by hot temperature activation directly releases residual stress from the previous cooling process. From this, it appears that double quenching produces high hardness and brittleness; therefore, tempering is required. The microstructure of $\mathrm{Q}_{900+800} \& \mathrm{~T}$ Steel and $Q_{900+750} \& T$ Steel specimens is similar. The hardness and compressive residual stress of the $\mathrm{Q}_{900+800} \& \mathrm{~T}$ Steel specimen decreased by heat activation of tempering. Activation occurs when heating to the $\mathrm{Ar}_{3}$ temperature. Fig. 11 shows the $\mathrm{Q}_{900+800} \& \mathrm{~T}$ Steel specimens.

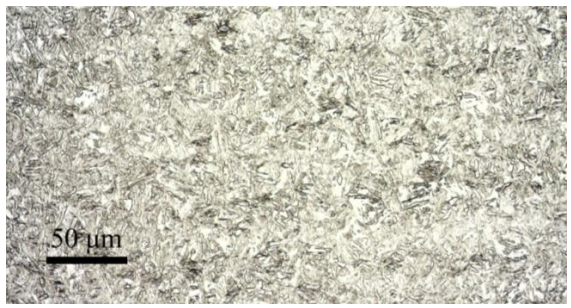

Fig. 11. $Q_{900+800} \& T$ Steel

Refinement occurs when heat activation is below the eutectoid line and coarsen in a zone far from the $\mathrm{Ar}_{3}$ line, and residual stress relief. The second quenching refines the original microstructure of the first quenching temperature. The fine structure increases the toughness, and with a temperature of $150{ }^{\circ} \mathrm{C}$, the martensite reduces slightly, and the residual stress. Fig. 12 shows the $Q_{900+850} \& \mathrm{~T}$ Steel specimen's microstructure, and the structure is refiner than in $\mathrm{Q}_{900+800} \& \mathrm{~T}$ Steel specimens.

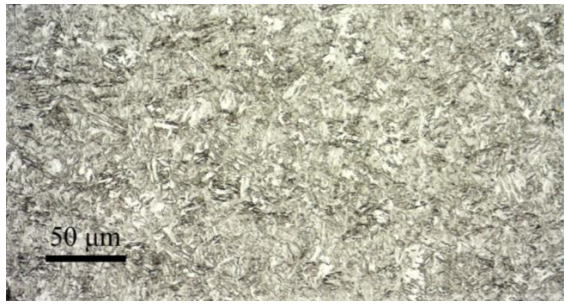

Fig. 12. $Q_{900+850} \& T$ Steel

The structure is similar to the samples before undergoing tempering heat treatment. In this specimen, there was martensite diffusion and a reduction in residual stress by activating tempering heat. The softening of the models results in stretching between microstructures (reduced compaction). Heat activation increases ductility, which directly reduces crack susceptibility. This condition facilitates the manufacturing process. This fine microstructure increases the material's ductility, decreases the cracking's susceptibility, and facilitates the manufacturing process. The second quenching shows grain structure refinement. But tempering relieves internal stress, and it increases ductility. Martensite is also slightly defused by tempering, which reduces hardness. Fig. 13 shows the Q $900+900$ \& T Steel specimens.



Fig. 13. Q900+900\&T Steel

In general, the martensite content in DQ\&T Steel is refiner than in Q\&T Steel. Fine martensite is due to the austenitization of the remaining first quenched austenite.

\section{Conclusions}

1. The formation of martensite is achieved during quenching from $357^{\circ} \mathrm{C}$ to $137^{\circ} \mathrm{C}$ (average value). Hardness depends on the tempering temperature used to avoid martensite decomposition.

2. The average hardness of Medium-Carbon and Carbon-Manganese Steel is around 287.7 BHN. While in the form of Q\&T Steel and DQ\&T Steel, it has 495 BHN and 479.7 BHN, respectively.

3. Impact energy of Medium-Carbon and Carbon-Manganese Steel is around 69.67 Joule, $Q_{900} \& \mathrm{~T}$ Steel $=36.67 \mathrm{Joule}$ (conventional), and $Q_{900+850} \& \mathrm{~T}$ Steel=43 Joule.

\section{Acknowledgments}

This research was conducted using Strategical Research funds with the 2020 Annual Work Plan and Budget (Rencana Kerja dan Anggaran Tahunan 2020 - RKAT 2020) funds. The authors would like to thank Mr. Amung Somantri, General Manager Material, and Products Development, PT. Krakatau Steel (Persero), Indonesia. The late Professor Rochim Suratman, Mechanical and Aerospace Engineering Faculty, Institute of Technology Bandung, for his support to our research.

\section{References}

1. Yurianto, Y., Suprihanto, A., Suryo, S. H., Umardani, Y., Yanuar, P. (2020). Effect of austenite temperature and holding time to impact energy and wear on HRP steel. Eastern-European Journal of Enterprise Technologies, 1 (12 (103)), 45-51. doi: https:// doi.org/10.15587/1729-4061.2020.156798

2. Lee, W.-S., Su, T.-T. (1999). Mechanical properties and microstructural features of AISI 4340 high-strength alloy steel under quenched and tempered conditions. Journal of Materials Processing Technology, 87 (1-3), 198-206. doi: https://doi.org/10.1016/ s0924-0136(98)00351-3 
3. Shimizu, K., Nishiyama, Z. (1972). Electron microscopic studies of martensitic transformations in iron alloys and steels. Metallurgical Transactions, 3 (5), 1055-1068. doi: https://doi.org/10.1007/bf02642437

4. Das, S. K., Thomas, G. (1969). Structure and mechanical properties of Fe-Ni-Co-C steels. Trans. ASM, 62, 659-668.

5. Krauss, G. (1999). Martensite in steel: strength and structure. Materials Science and Engineering: A, 273-275, 40-57. doi: https:// doi.org/10.1016/s0921-5093(99)00288-9

6. Silva, E. P., Pacheco, P. M. C. L., Savi, M. A. (2004). On the thermo-mechanical coupling in austenite-martensite phase transformation related to the quenching process. International Journal of Solids and Structures, 41 (3-4), 1139-1155. doi: https:// doi.org/10.1016/j.ijsolstr.2003.09.049

7. Ooki, C. (2004). Improving Rolling Contact Fatigue Life of Bearing Steels Through Grain Refinement. SAE Technical Paper Series. doi: https://doi.org/10.4271/2004-01-0634

8. Luxenburger, G., Bockelmann, M., Wolf, P., Hanus, F., Cawelius, R., Buchholz, J. (2004). High strength quenched and tempered $\left(Q^{+} \mathrm{T}\right)$ steels for pressure vessels. International Journal of Pressure Vessels and Piping, 81 (2), 159-171. doi: https:// doi.org/10.1016/j.ijpvp.2003.11.006

9. Madhusudhan Reddy, G., Mohandas, T., Papukutty, K. (1999). Enhancement of ballistic capabilities of soft welds through hardfacing. International Journal of Impact Engineering, 22 (8), 775-791. doi: https://doi.org/10.1016/s0734-743x(99)00020-2

10. Magudeeswaran, G., Balasubramanian, V., Madhusudhanreddy, G. (2008). Hydrogen induced cold cracking studies on armour grade high strength, quenched and tempered steel weldments. International Journal of Hydrogen Energy, 33 (7), 1897-1908. doi: https:// doi.org/10.1016/j.ijhydene.2008.01.035

11. Balakrishnan, M., Balasubramanian, V., Madhusudhan Reddy, G. (2013). Effect of hardfaced interlayer thickness on ballistic performance of armour steel welds. Materials \& Design, 44, 59-68. doi: https://doi.org/10.1016/j.matdes.2012.06.010

12. Lee, K. O., Hong, S. K., Kang, Y. K., Yoon, H. J., Kang, S. S. (2009). Grain refinement in bearing steels using a double-quenching heat-treatment process. International Journal of Automotive Technology, 10 (6), 697-702. doi: https://doi.org/10.1007/s12239009-0082-5

13. Di Schino, A., Guarnaschelli, C. (2009). Effect of microstructure on cleavage resistance of high-strength quenched and tempered steels. Materials Letters, 63 (22), 1968-1972. doi: https://doi.org/10.1016/j.matlet.2009.06.032

14. Nishibata, T., Kojima, N. (2013). Effect of quenching rate on hardness and microstructure of hot-stamped steel. Journal of Alloys and Compounds, 577, S549-S554. doi: https://doi.org/10.1016/j.jallcom.2011.12.154

15. Khani Sanij, M. H., Ghasemi Banadkouki, S. S., Mashreghi, A. R., Moshrefifar, M. (2012). The effect of single and double quenching and tempering heat treatments on the microstructure and mechanical properties of AISI 4140 steel. Materials \& Design, 42, 339-346. doi: https://doi.org/10.1016/j.matdes.2012.06.017

16. Yurianto, Pratikto, Sonoko, R., Wahyono, Bayuseno, A. P. (2018). Quenching and tempering parameter on Indonesian hot rolled plate steel for armour steel. MATEC Web of Conferences, 204, 05001. doi: https://doi.org/10.1051/matecconf/201820405001

17. Sampath, K. (2007). How to Choose Electrodes for Joining High-Strength Steels. Welding Journal, 26-28.

18. ASM Handbook (1996). Vol. 6. Properties and Selection: Irons, Steels, and High Performance Alloys. Copyright ASM International, 246-247.

19. Bailey, N., Coe, F. R., Googh, T. G., Hart, P. H. M., Jenkins, N., Pargetter, R. J. (1973). Welding steels without hydrogen cracking. Abington Publishing and ASM International.

20. Lee, H.-G. (1999). Chemical Thermodynamics For Metals and Materials. World Scientific Publishing Co Pte Ltd. doi: https:// doi.org/10.1142/p152

21. ASTM E23-07a. Standard Test Methods for Notched Bar Impact Testing of Metallic Materials (2007). ASTM International, West Conshohocken, PA. doi: https://doi.org/10.1520/e0023-07a 